\title{
Pengaruh Disiplin Kerja dan Pemberian Insentif terhadap Kinerja Karyawan PT Putra Karisma Palembang
}

\author{
Andini Dwi Saputri ${ }^{1)}$, Susi Handayani ${ }^{2)}$, Muhammad Kurniawan DP ${ }^{3)}$ \\ Universitas Indo Global Mandiri, Palembang, Indonesia \\ andinidwisaputri4@gmail.com ${ }^{1)}$,susihandayani25@yahoo.co.id²),kurniawan@uigm.ac.id ${ }^{3)}$
}

\begin{abstract}
This study aims to analyze the effects of work discipline and incentives on the performance of employees of PT Putra Karisma Palembang. The sample was selected using the saturated sample technique. Data from 57 respondents were collected through interviews, documentation, and questionnaires. This study implemented the multiple linear regression method to analyze data. The results prove that partially each of work discipline and incentives has no significant effect on employee performance. However, simultaneously work discipline and incentives have a significant effect on employee performance. This insight is beneficial for PT Putra Karisma Palembang. To improve employees' performance, the company should consider both work discipline and incentives factors together.
\end{abstract}

Keywords: Work Discipline, Incentives, Employee Performance, HR Management

\begin{abstract}
Abstrak
Penelitian ini bertujuan untuk menganalisis pengaruh disiplin kerja dan pemberian insentif terhadap kinerja karyawan PT Putra Karisma Palembang. Sampel dipilih menggunakan teknik sampel jenuh. Data 57 responden dikumpulkan melalui wawancara, dokumentasi, dan kuesioner. Studi ini mengimplementasikan metode regresi linier berganda untuk menganalisis data. Hasil investigasi membuktikan bahwa secara parsial baik disiplin kerja maupun pemberian insentif masing-masing tidak berpengaruh signifikan terhadap kinerja karyawan. Tetapi, secara simultan disiplin kerja dan pemberian insentif berpengaruh signifikan terhadap kinerja karyawan. Fakta ini bermanfaat bagi PT Putra Karisma Palembang. Untuk meningkatkan kinerja karyawan, maka perusahaan harus mempertimbangkan faktor disiplin kerja dan pemberian insentif secara bersama-sama.
\end{abstract}

Kata Kunci: disiplin kerja, pemberian insentif, kinerja karyawan, manajemen SDM

\section{Pendahuluan}

\subsection{Latar Belakang}

Salah satu unsur penting dalam pengembangan sumber daya manusia yaitu disiplin kerja, dengan adanya disiplin kerja maka kegiatan yang dilakukan didalam perusahaan akan sesuai dengan harapan. Menurut Edy Sutrisno (2016:89) Disiplin adalah perilaku seseorang yang sesuai dengan peraturan, prosedur kerja yang ada atau disiplin adalah sikap, tingkah laku dan perbuatan yang sesuai dengan peraturan dari organisasi baik tertulis maupun tidak tertulis. Sikap disiplin tinggi yang diterapkan oleh karyawan mencerminkan karyawan tersebut mempunyai rasa tanggung jawab yang besar terhadap tugas-tugasnya sehingga mendorong semangat dalam bekerja untuk terwujudnya tujuan perusahaan dengan menaati peraturan serta norma-norma sosial yang berlaku diperusahaan. Maka dari itu penerapan sikap disiplin kerja terhadap karyawan sangat mendukung pencapaian sasaran dan tujuan perusahaan. Selain disiplin kerja, pemberian insentif juga termasuk unsur penting dalam upaya pengembangan Sumber daya manusia, insentif adalah salah satu jenis penghargaan yang dikaitkan dengan penilaian kerja karyawan. Mangkunegara (2011:89) Insentif adalah suatu bentuk uang yang 
diberikan oleh pihak pemimpin organisasi kepada karyawan agar mereka bekerja dengan motivasi yang tinggi dan berprestasi dalam mencapai tujuan tujuan organisasi sebagai pengakuan prestasi kerja dan kontribusi karyawan kepada organisasi. pemberian insentif kepada karyawan bertujuan untuk memacu semangat kerja karyawan dalam mencapai prestasi kerja serta memotivasi karyawan untuk memberikan kontribusi yang lebih kepada perusahaan dalam mencapai tujuannya (Yeri dkk, 2017). Menurut Hasibuan (2013) mengatakan bahwa, insentif diberikan dengan tujuan memberikan rangsangan dan motivasi kepada karyawan untuk meningkatkan prestasi kerja, serta efisiensi, dan efektivitas produksi. Pemberian insentif termasuk kedalam hal pokok yang harus diperhatikan oleh perusahaan, karena dengan adanya insentif karyawan merasa memiliki motivasi untuk terus meningkatkan kualitas kerjanya.

\subsection{Rumusan Masalah}

1.Bagaimana disiplin kerja berpengaruh terhadap kinerja karyawan PT. Putra Karisma Palembang?

2.Bagaimana pemberian insentif berpengaruh terhadap kinerja karyawan PT. Putra Karisma Palembang?

3. Bagaimana disiplin kerja dan pemberian insentif berpengaruh terhadap kinerja karyawan PT. Putra Karisma Palembang?

\subsection{Tujuan Penelitian}

1. Untuk mengetahui pengaruh disiplin kerja terhadap kinerja karyawan PT. Putra Karisma

2. Untuk mengetahui pengaruh pemberian insentif terhadap kinerja karyawan PT. Putra Karisma

3. Untuk mengetahui pengaruh disiplin kerja dan pemberian insentif terhadap karyawan PT. Putra Karisma.

\section{Tinjauan Pustaka}

\subsection{Pengertian Manajemen Sumber Daya Manusia}

Manajemen Sumber Daya Manusia merupakan salah satu bidang dari manajemen umum yang meliputi segi perencanaan, pengorganisasian, pelaksanaan dan pengendalian, (Rivai dan Sagala dalam Priansa 2014:21).

\subsection{Disiplin Kerja}

Menurut Hasibuan (2014:190) Disiplin Kerja adalah Kesadaran dan kesediaan seseorang untuk menaati semua peraturan perusahaan dan norma-norma sosial yang berlaku.

\subsection{Indikator- Indikator Disiplin Kerja}

1. Ketepatan waktu datang ke tempat kerja.

2. Ketepatan jam pulang ke rumah.

3. Kepatuhan terhadap peraturan yang berlaku.

Penggunaan seragam kerja yang telah ditentukan.

4. Tanggung jawab dalam mengerjakan tugas.

Melaksanakan tugas-tugas kerja sampai selesai setiap harinya (Mangkunegara \& Octorent, 2015) 


\subsection{Pengertian Insentif}

Menurut A.A. Anwar Prabu Mangkunegara (2011:89) insentif kerja adalah suatu penghargaan dalam bentuk uang yang diberikan oleh pihak pemimpin organisasi kepada karyawan agar mereka bekerja dengan motivasi yang tinggi dan berprestasi dalam mencapai tujuan-tujuan organisasi atau dengan kata lain insentif kerja merupakan pemberian uang diluar gaji yang dilakukan oleh pihak pemimpin organisasi sebagai pengakuan terhadap prestasi kerja dan kontribusi karyawan kepada organisasi.

\subsection{Indikator-Indikator Insentif}

Menurut Sarwoto (2010:156) terbagi menjadi 2

\section{Insentif Material}

a) Bonus

b) Komisi

c) Berbagi keuntungan

d) kompensasi yang ditangguhkan

\section{Insentif non material}

a) Pemberian gelar secara resmi

b) tanda jasa/ medali

c) pemberian piagam penghargaan

d) pujiam ;isan atau tulisan

e) pemberian promosi

f) hak untuk memakai atribut jabatan

g) perlengkapan khusus

h) ucapan terimakasih formal/nonformal

\subsection{Kinerja Karyawan}

Menurut Anwar Prabu Mangkunegara (2015:67) Kinerja adalah hasil kerja secara kualitas dan kuantitas yang dicapai oleh seorang pegawai dalam melaksanakan tugasnya sesuai dengan tanggung jawab yang diberikan kepadanya.

\subsection{Indikator-Indikator Kinerja Karyawan}

Menurut (Mangkunegara 2011:75) indicator kinerja karyawan adalah
a) Kualitas kerja
b) kuantitas kerja
c) pelaksanaan tugas
d) tanggung jawab 


\section{MetodePenelitian}

\subsection{Waktu dan Tempat Penelitian}

Waktu Penelitian ini berlangsung selama kurang lebih 4 bulan dimulai sejak bulan Oktober, dilakukan sejak adanya izin penelitian hingga proses bimbingan berlangsung, Tempat penelitian dilaksanakan di PT. Putra Karisma yang beralamat di JL. Mayor Ruslan No.3, 9 Ilir, Kec. Ilir Timur II, Kota Palembang, Sumatera Selatan 30114.

\subsection{Jenis dan Sumber Data}

Menurut Sugiyono (2015), jenis data dibedakan menjadi dua, yaitu kualitatif dan kuantitatif:

a) Data Kualitatif

Sugiyono (2015) Pengertian data kualitatif adalah data yang berbentuk kata, skema, dan gambar.

b) Data Kuantitatif

Sugiyono (2015) Pengertian data kuantitatif adalah data yang berbentuk angka atau data kualitatif yang diangkakan. Peneliti menggunakan jenis data ini dalam penelitian dengan cara menyebar kuesioner yang berisi pertanyaan yang sudah diberi skor atau dalam skala 1-5, dan hasilnya akan dihitung dengan teknik statistik.

Menurut (Sugiyono, 2015) Sumber data penelitian dibedakan menjadi dua, yaitu sumber data primer dan sumber data sekunder :

a) Data Primer

Menurut Sugiyono (2015) Data primer adalah sumber data yang langsung memberikan data kepada pengumpul data. Peneliti akan menggunakan sumber data ini, sumber data ini dapat diperoleh melalui kuesioner dan

yang sudah diberi pertanyaan dengan skor / skala 1-5, dan wawancara yang dilakukan peneliti di PT. Putra Karisma kepada Karyawan PT. Putra Karisma.

b) Data Sekunder

Pengertian data sekunder menurut Sugiyono (2015) adalah sumber data yang tidak langsung memberikan data kepada pengumpul data, misalnya lewat orang lain atau lewat dokumen.

\subsection{Teknik Pengumpulan Data}

A. Wawancara

Sugiyono (2017:194) Wawancara digunakan sebagai teknik pengumpulan data apabila peneliti ingin melaksanakan studi pendahuluan untuk menemukan permasalahan yang akan diteliti, dan apabila peneliti juga ingin mengetahui hal-hal dari responden yang lebih mendalam dan jumlah dari responden tersebut sedikit. Wawancara dilakukan penulis kepada karyawan PT. Putra Karisma Palembang.

B. Kuesioner

Menurut Sugiyono (2017:199) Kuesioner adalah teknik pengumpulan data yang dilakukan dengan cara memberi seperangkat pertanyaan atau pernyataan tertulis kepada responden untuk dijawabnya. Pemberian kuesioner ditujukan kepada seluruh karyawan PT. Putra Karisma Palembang.

C. Dokumentasi 
Menurut Sugiyono (2015;329) Dokumentasi adalah suatu cara yang digunakan untuk memperoleh data dan informasi dalam bentuk buku, arsip, dokumen, tulisan angka dan gambar yang berupa laporan serta keterangan yang dapat mendukung penelitian.

\subsection{Populasi dan Sampel}

\section{A. Populasi}

Wiyono (2011:75) Mengemukakan bahwa populasi bukan hanya orang, tetapi juga obyek dan benda-benda alam yang lain. Populasi juga bukan sekedar jumlah yang ada pada obyek atau subyek penelitian, tetapi meliputi seluruh karakteristik atau ciri-ciri yang dimiliki oleh subyek atau obyek itu. Populasi di penelitian ini adalah seluruh karyawan PT. Putra Karisma Palembang yang berjumlah 57 orang.

\section{B. Sampel}

Arikunto (2013:174) mendefinisikan sampel adalah sebagian atau wakil populasi yang diteliti. pengambilan sampel dalam penelitian ini dengan menggunakan Non probability sampling melalui teknik Sampling jenuh. Teknik sampling jenuh merupakan teknik penentuan sampel bila semua anggota populasi digunakan sebagai sampel, Sugiyono (2014:68). sampel diambil dari seluruh anggota populasi yaitu Karyawan PT. Putra Karisma yang berjumlah 57 responden.

\subsection{Teknik Analisis Data}

\section{Uji Validitas}

Validitas adalah suatu ukuran yang menunjukkan tingkat-tingkat kevalidan atau kesahihan sesuatu instrumen, Arikunto (2010:211). Teknik pengujian yang digunakan dalam penelitian ini adalah menggunakan Korelasi Bivariate Pearson, taraf signifikan 0,05 apabila nilai signifikannya $\geq 0,05$ maka instrumen pertanyaan dianggap valid. Sebaliknya, jika nilai signifikannya $\leq 0,05$ maka instrumen pertanyaan tersebut tidak valid.

\section{Uji Reliabilitas}

Menurut Ghozali (2016:48) Reliabilitas sebenarnya adalah alat untuk mengukur suatu kuesioner yang merupakan indikator dari variabel atau konstruk. Dalam penelitian ini dalam menguji reliabilitas masing-masing instrumen penulis menggunakan uji statistik Cronbach Alpha $(\alpha)$. Perhitungan reliabilitas dengan Cronbach Alpha $(\alpha)$ instrumen dikatakan reliabel jika dinilai Cronbach Alphanya> 0,60.

\section{Uji Normalitas}

Menurut Ghozali (2013: 160) mengemukakan bahwa uji normalitas bertujuan untuk mengetahui apakah masing-masing variabel berdistribusi normal atau tidak, untuk menguji suatu data berdistribusi normal atau tidak, dapat diketahui dengan menggunakan Histogram Dependent dan Grafik normal P-Plot melalui bantuan SPSS for windows.

\section{Uji Hipotesis}

Uji Hipotesis digunakan untuk memperkuat hasil perhitungan yaitu dengan menggunakan uji $\mathrm{f}$ dan uji t,Uji t digunakan untuk menentukan tingkat signifikan pengaruh masing-masing variabel independen terhadap dependen. Sedangkan uji F digunakan untuk menentukan tingkat signifikan pengaruh seluruh variabel independen serta simultan terhadap variabel dependen.

\section{Analisis Regresi Linier Berganda}


Menurut Sugiyono (2016:275) analisis regresi linier berganda merupakan regresi yang memiliki satu variabel dependent dan dua atau lebih variabel independent.

Rumus Perhitungannya adalah sebagai berikut:

$$
\mathbf{Y}=\mathbf{a}+\mathbf{b}_{1} \mathbf{X}_{1}+\mathbf{b}_{2} \mathbf{X}_{2}+\mathbf{e}
$$

Keterangan :

Y : Variabel Kinerja Karyawan

a : Konstanta

$\mathrm{b}_{1} \quad$ : Koefisien regresi untuk $\mathrm{X}_{1}$

$\mathrm{b}_{2} \quad$ : Koefisien regresi untuk $\mathrm{X}_{2}$

$\mathrm{X}_{1} \quad$ : Disiplin Kerja

$\mathrm{X}_{2} \quad$ : Pemberian Insentif

e : Nilai Residu

\section{Koefisien Korelasi}

Koefisien korelasi $\mathrm{r}$ menunjukan derajat korelasi antara variabel independen $(\mathrm{X})$ dan variabel dependen (Y). Nilai koefisien harus terdapat dalam batas-batas -1 hingga $+1(-1<\mathrm{r} \leq+1)$, yang menghasilkan beberapa kemungkinan, yaitu:

1) Tanda positif menunjukkan adanya korelasi positif antara variabel-variabel yang diuji, yang berarti setiap kenaikan dan penurunan nilai-nilai $\mathrm{X}$ akan diikuti dengan kenaikan dan penurunan $\mathrm{Y}$.

2) Tanda negatif menunjukkan adanya korelasi negatif antara variabel-variabel yang diuji, yang berarti setiap kenaikan nilai-nilai $\mathrm{X}$ akan diikuti dengan penurunan $\mathrm{Y}$

3) dan sebaliknya Jika $r=0$ atau mendekati 0 , maka menunjukkan korelasi yang lemah atau tidak ada korelasi sama sekali antara variabel-variabel yang diteliti. Untuk dapat memberikan penafsiran besar kecilnya koefisien korelasi,

Menurut Sugiyono (2017:231) ada beberapa pedoman untuk memberikan interprestasi koefisien korelasi diantaranya adalah :

Tabel 3.2. Interprestasi koefisien korelasi (R)

\begin{tabular}{|l|l|}
\hline Besarnya Pengaruh & Tingkat Hubungan \\
\hline $0,00-0,199$ & Sangat Lemah \\
\hline $0,20-0,339$ & Lemah \\
\hline $0,40-0,599$ & Sedang \\
\hline
\end{tabular}




\begin{tabular}{|l|l|}
\hline $0,60-0,799$ & Kuat \\
\hline $0,80-1,000$ & Sangat Kuat \\
\hline
\end{tabular}

Sumber Buku Sugiyono (2017)

\section{Koefisien Determinasi $\left(\mathrm{R}^{2}\right)$}

Menurut Imam Ghazali (2013:97) Koefisien determinasi ( $\left.\mathrm{R}^{2}\right)$ pada intinya mengukur seberapa jauh kemampuan model dalam menerangkan variasi variabel independent. Nilai koefisien determinasi adalah nol dan satu. Nilai $\mathrm{R}^{2}$ yang kecil berarti kemampuan variabel-variabel independent dalam menjelaskan variasi variabel dependent amat terbatas. Nilai yang mendekati satu berarti variabel-variabel independent memberikan hampir semua informasi yang dibutuhkan untuk memprediksi variasi variabel dependent.

\section{Hasil dan Diskusi}

Dalam bab ini akan membahas mengenai analisis data yang diperoleh dari kuesioner yang telah dibagikan kepada 57 responden yang terdiri dari karyawan PT. Putra Karisma, dalam melakukan analisis data ini peneliti menggunakan SPSS V23 sehingga diperoleh hasil penelitian.

\subsection{Uji Validitas}

Tabel 4.1. Validitas Variabel Disiplin Kerja $\left(\mathrm{X}_{1}\right)$

\begin{tabular}{|c|c|c|c|}
\hline Pernyataan & R-hitung & R-tabel & Keterangan \\
\hline DK1 & 0,779 & 0,2609 & Valid \\
\hline DK2 & 0,843 & 0,2609 & Valid \\
\hline DK3 & 0,773 & 0,2609 & Valid \\
\hline DK4 & 0,869 & 0,2609 & Valid \\
\hline DK5 & 0,890 & 0,2609 & Valid \\
\hline DK6 & 0,880 & 0,2609 & Valid \\
\hline
\end{tabular}

Sumber: Pengelolaan data dengan SPSS V23

Berdasarkan tabel 4.1 didapat hasil pengujian validitas untuk keenam item pertanyaan kuesioner disiplin kerja $\left(\mathrm{X}_{1}\right)$ diperoleh nilai diatas $\mathrm{r}$ tabel 0,2609 dengan membandingkan nilai $\mathrm{r}$ hitung (correlated item-total correlation) dengan nilai $\mathrm{r}$ table, jika $\mathrm{r}$ hitung $>\mathrm{r}$ tabel dan nilai positif maka butir pertanyaan tersebut dinyatakan valid, semua nilai $r$ hitung lebih besar dari $r$ tabel $(0,2609)$, hal ini berati alat ukur berupa pertanyaan kuesioner telah memiliki tingkat validitas yang baik. 
Tabel 4.2. Validitas Variabel Pemberian Insentif

\begin{tabular}{|c|c|c|c|}
\hline Pernyataan & R-hitung & R-tabel & Keterangan \\
\hline PI1 & 0,779 & 0,2609 & Valid \\
\hline PI2 & 0,876 & 0,2609 & Valid \\
\hline PI3 & 0,783 & 0,2609 & Valid \\
\hline PI4 & 0,275 & 0,2609 & Valid \\
\hline PI5 & 0,802 & 0,2609 & Valid \\
\hline
\end{tabular}

Sumber: Pengelolaan data dengan SPSS V23

Berdasarkan tabel 4.2 didapat hasil pengujian validitas untuk kelima item pertanyaan kuesioner pemberian insentif $\left(\mathrm{X}_{2}\right)$ diperoleh nilai diatas $\mathrm{r}$ tabel 0,2609 dengan membandingkan nilai $\mathrm{r}$ hitung (correlated item-total correlation) dengan nilai $r$ table, jika $r$ hitung $>r$ tabel dan nilai positif maka butir pertanyaan tersebut dinyatakan valid, semua nilai $r$ hitung lebih besar dari $r$ tabel $(0,2609)$, hal ini berati alat ukur berupa pertanyaan kuesioner telah memiliki tingkat validitas yang baik.

Tabel 4.3. Validitas Variabel Kinerja Karyawan

\begin{tabular}{|c|c|c|c|}
\hline Pernyataan & R-hitung & R-tabel & Keterangan \\
\hline KK1 & 0,723 & 0,2609 & Valid \\
\hline KK2 & 0,795 & 0,2609 & Valid \\
\hline KK3 & 0,840 & 0,2609 & Valid \\
\hline KK4 & 0,878 & 0,2609 & Valid \\
\hline KK5 & 0,631 & 0,2609 & Valid \\
\hline
\end{tabular}

Sumber: Pengelolaan data dengan SPSS V23

Berdasarkan tabel 4.3 didapat hasil pengujian validitas untuk kelima item pertanyaan kuesioner kinerja karyawan (Y) diperoleh nilai diatas $r$ tabel 0,2609 dengan membandingkan nilai $r$ hitung (correlated item-total correlation) dengan nilai $r$ table, jika $r$ hitung $>r$ tabel dan nilai positif maka butir pertanyaan tersebut dinyatakan valid, semua nilai $r$ hitung lebih besar dari $r$ tabel $(0,2609)$, hal ini berati alat ukur berupa pertanyaan kuesioner telah memiliki tingkat validitas yang baik. 


\subsection{Uji Reliabilitas}

Tabel 4.4. Hasil Uji Reliabilitas

\begin{tabular}{|c|c|c|c|}
\hline Variabel & $\begin{array}{c}\text { Cronbach's } \\
\text { Alpha }\end{array}$ & $\begin{array}{c}\text { Standar } \\
\text { Reliabilitas }\end{array}$ & Keterangan \\
\hline Disiplin Kerja & 0,920 & 0,60 & Reliabel \\
\hline Pemberian Insentif & 0,761 & 0,60 & Reliabel \\
\hline Kinerja Karyawan & 0,805 & 0,60 & \\
\hline
\end{tabular}

Sumber: Pengelolaan data dengan SPSS V23

Berdasarkan tabel 4.4 Nilai Cronbach's Alpha semua variabel lebih besar dari 0,60 sehingga dapat disimpulkan indikator atau kuesioner digunakan variabel Disiplin Kerja, Pemberian Insentif, Kinerja Karyawan semua dikatakan reliabel dan dapat dipercaya sebagai alat ukur variabel.

\subsection{Uji Normalitas}

Menurut Ghozali (2013: 160) mengemukakan bahwa uji normalitas bertujuan untuk mengetahui apakah masing-masing variabel berdistribusi normal atau tidak, untuk menguji suatu data berdistribusi normal atau tidak, dapat diketahui dengan menggunakan grafik normal plot. Dengan melihat histogram dari residualnya. Dasar pengambilan keputusan Ghozali,( 2011: 163) :

a. Jika data menyebar disekitar garis diagonal dan mengikuti arah garis diagonal atau grafik histogramnya menunjukkan pola distribusi normal, maka model regresi memenuh asumsi normalitas.

b. Jika data menyebar jauh dari diagonal dan tidak mengikuti arah garis diagonal atau grafik histogram tidak menunjukkan pola distribusi normal, maka model regresi tidak memenuhi asumsi normalitas.

Gambar 4.1. Histogram Dependen

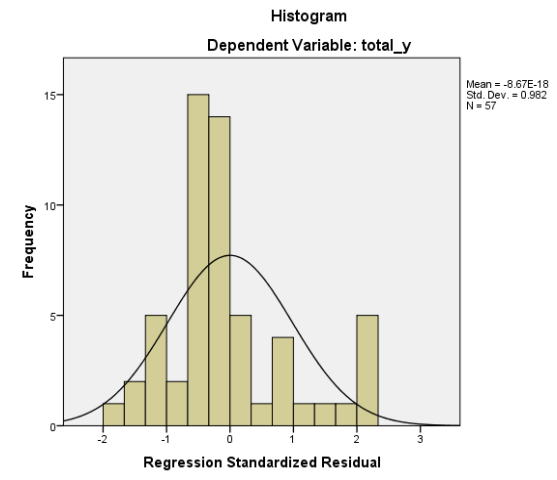


Berdasarkan gambar 4.1, tampilan grafik normal Plot yang tersaji diatas dapat disimpulkan bahwa grafik histogram memberikan pola distribusi yang normal.

Gambar 4.2. Grafik normal P-P Plott of Regression Standarized Residual

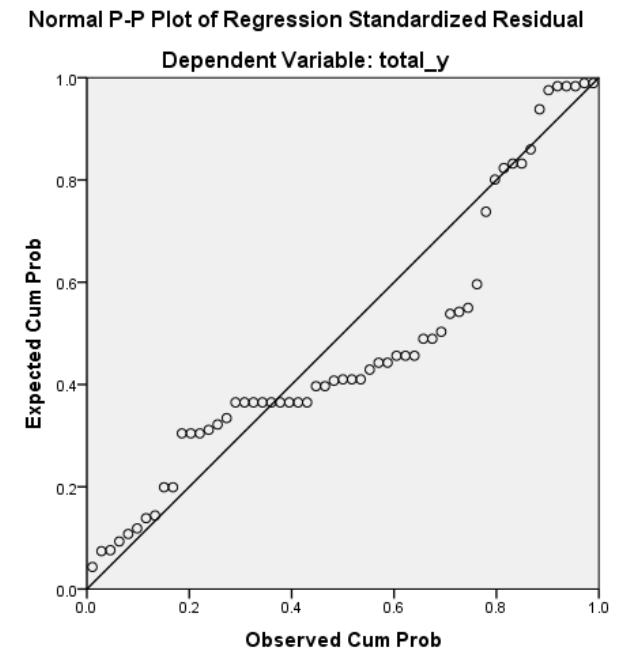

Berdasarkan gambar 4.2 grafik $P-P$ Plot juga menunjukan kesimpulan, dari tampilan di atas terlihat bahwa ada data yang menyebar keluar sedikit dari garis diagonal, hingga masih dapat dikatakan normal.

\subsection{Hasil Uji Hipotesis}

Tabel 4.5 Uji T Variabel Disiplin Kerja

Coefficients $^{\mathrm{a}}$

\begin{tabular}{|c|c|c|c|c|c|}
\hline \multirow[b]{2}{*}{ Model } & \multicolumn{2}{|c|}{ Unstandardized Coefficients } & \multirow{2}{*}{$\begin{array}{c}\begin{array}{c}\text { Standardized } \\
\text { Coefficients }\end{array} \\
\text { Beta }\end{array}$} & \multirow[b]{2}{*}{$\mathrm{t}$} & \multirow[b]{2}{*}{ Sig. } \\
\hline & B & Std. Error & & & \\
\hline 1 (Constant) & 16.819 & 2.137 & & 7.872 & .000 \\
\hline total $\times 1$ & .146 & .083 & .230 & 1.753 & .085 \\
\hline
\end{tabular}

a. Dependent Variable: total_y

Sumber data diolah dengan SPSS V.23

Pada tabel 4.5 dihasilkan t-hitung sebesar 1,753 pada tingkat sig sebesar 0,085 Hasil uji-t tersebut dikaitkan dengan hipotesis yang diajukan dalam penelitian ini. 
Kriteria diterimanya hipotesis apabila :

a. Jika t-hitung $>\mathrm{t}$-tabel sig $<0,05$, maka $\mathrm{H} 1$ diterima.

b. Taraf nyata $=5 \%$ drajat kebebasan $(\mathrm{df})=(\alpha / 2 ; n-K-1)=(0,05 / 2 ; 57-3-1)=(0,025$ ; 53) $=2,005$

Keterangan : $\mathrm{K}=$ Jumlah Variabel

$$
\mathrm{n}=\text { Jumlah Sampel }
$$

H1 : Menunjukan tidak terdapat pengaruh disiplin kerja terhadap kinerja karyawan PT. Putra Karisma Palembang.

Diketahui nilai Sig untuk Disiplin kerja $\left(\mathrm{X}_{1}\right)$ terhadap Kinerja Karyawan $(\mathrm{Y})$ adalah sebesar $0,085>0,05$ dan nilai $t$ hitung $1,753<\mathrm{t}$ tabel 2,005, sehingga dapat disimpulkan bahwa $\mathrm{H} 1$ ditolak yang berarti Disiplin Kerja $\left(\mathrm{X}_{1}\right)$ tidak berpengaruh secara signifikan terhadap Kinerja Karyawan (Y) pada PT. Putra Karisma Palembang.

Tabel 4.6 Uji T Variabel Pemberian Insentif

\section{Coefficients $^{\mathrm{a}}$}

\begin{tabular}{|c|c|c|c|c|c|}
\hline \multirow[b]{2}{*}{ Model } & \multicolumn{2}{|c|}{ Unstandardized Coefficients } & \multirow{2}{*}{$\begin{array}{c}\begin{array}{c}\text { Standardized } \\
\text { Coefficients }\end{array} \\
\text { Beta }\end{array}$} & \multirow[b]{2}{*}{$\mathrm{t}$} & \multirow[b]{2}{*}{ Sig. } \\
\hline & $\mathrm{B}$ & Std. Error & & & \\
\hline 1 (Constant) & 16.700 & 1.990 & & 8.392 & .000 \\
\hline total_x2 & .205 & .105 & .254 & 1.944 & .057 \\
\hline
\end{tabular}

a. Dependent Variable: total_y

Sumber data diolah dengan SPSS V.23

Pada tabel 4.6 dihasilkan t-hitung sebesar 1,944 pada tingkat sig sebesar 0,057 Hasil uji-t tersebut dikaitkan dengan hipotesis yang diajukan dalam penelitian ini.

Kriteria diterimanya hipotesis apabila :

a. Jika t-hitung $>$ t-tabel sig $<0,05$, maka $\mathrm{H} 2$ diterima.

b. $\quad$ Taraf nyata $=5 \%$ drajat kebebasan $(\mathrm{df})=(\alpha / 2 ; \mathrm{n}-\mathrm{K}-1)=(0,05 / 2 ; 57-3-1)=(0,025$; $53)=2,005$

Keterangan : $\mathrm{K}=$ Jumlah Variabel

$$
\mathrm{n}=\text { Jumlah Sampel }
$$

H2 : Menunjukan tidak terdapat pengaruh pemberian insentif terhadap kinerja karyawan PT. Putra Karisma Palembang. 
Diketahui nilai Sig untuk Pemberian Insentif $\left(\mathrm{X}_{2}\right)$ terhadap Kinerja Karyawan $(\mathrm{Y})$ adalah sebesar 0,057 >0,05 dan nilai thitung 1,944 < t tabel 2,005, sehingga dapat disimpulkan bahwa $\mathrm{H} 2$ ditolak yang berarti Pemberian Insentif $\left(\mathrm{X}_{2}\right)$ tidak berpengaruh secara signifikan terhadap Kinerja Karyawan (Y) pada PT. Putra Karisma Palembang.

\section{Uji Simultan (Uji F)}

Uji ini bertujuan untuk menunjukkan apakah variabel independent yang dimaksudkan dalam model mempunyai pengaruh secara bersama-sama terhadap variabel dependent, ( Rachmawati dkk, 2015).

Tabel 4.7 Uji Simultan

ANOVA $^{\mathrm{a}}$

\begin{tabular}{|l|r|r|r|r|r|}
\hline Model & Sum of Squares & df & Mean Square & F & Sig. \\
\hline 1 Regression & 19.426 & 2 & 9.713 & 3.434 & $.039^{\mathrm{b}}$ \\
Residual & 152.715 & 54 & 2.828 & & \\
Total & 172.140 & 56 & & & \\
\hline
\end{tabular}

a. Dependent Variable: total_y

b. Predictors: (Constant), total_x2, total_x1

Sumber data diolah dengan SPSS V.23

Dengan dasar pengambilan keputusan menurut (Sujarweni 2015:95) :

1. Pengambilan keputusan berdasarkan nilai probabilitas :

a) Jika signifikan $\alpha<$ tingkat kesalahan $(\alpha<0,05)$, maka H3 diterima.

2. Pengambilan keputusan berdasarkan nilai F hitung :

a) Jika F-hitung > F-tabel maka H3 diterima.

Dengan penentuan F-tabel :

Derajat kepercayaan 5\%dimana :

$\mathrm{V} 1=\mathrm{K}=2 \quad(\mathrm{~K}=\mathrm{Jumlah}$ variabel independen $)$

$\mathrm{V} 2=\mathrm{n}-\mathrm{K}-1=57-2-1=54 \rightarrow \mathrm{f}$ tabel $(=2 ; 54)$

Maka, didapat nilai $\mathrm{F}$ tabel $=3,17$

Karena nilai $\mathrm{F}$ hitung $(3,434)>$ nilai $\mathrm{F}$ tabel $(3,17)$ dan nilai signifikansi $\mathrm{F}(0,039)<$ tingkat kesalahan $(\alpha=0,05)$, maka H3 diterima, sehingga dapat disimpulkan Disiplin kerja dan Pemberian Insentif berpengaruh positif dan signifikan terhadap kinerja karyawan PT. Putra Karisma Palembang, Hal ini berarti hipotesis ketiga penelitian dapat diterima. 


\subsection{Uji Analisis Regresi Berganda}

4.8 Tabel Uji Analisis Regresi Berganda

Coefficients ${ }^{\mathbf{a}}$

\begin{tabular}{|c|c|c|c|c|c|}
\hline \multirow[b]{2}{*}{ Model } & \multicolumn{2}{|c|}{ Unstandardized Coefficients } & \multirow{2}{*}{$\begin{array}{c}\begin{array}{c}\text { Standardized } \\
\text { Coefficients }\end{array} \\
\text { Beta }\end{array}$} & \multirow[b]{2}{*}{$\mathrm{t}$} & \multirow[b]{2}{*}{ Sig. } \\
\hline & $\mathrm{B}$ & Std. Error & & & \\
\hline 1 (Constant) & 13.262 & 2.797 & & 4.741 & .000 \\
\hline total_x1 & .140 & .082 & .220 & 1.719 & .091 \\
\hline total_x2 & .198 & .104 & .245 & 1.910 & .061 \\
\hline
\end{tabular}

a. Dependent Variable: total_y

Sumber data diolah dengan SPSS V.23

Berdasarkan hasil pengelolaan data yang terlihat pada tabel 4.8 pada kolom unstandardized coefficients bagian B diperoleh model persamaan regresi linear berganda sebagai berikut:

\section{$\mathrm{Y}=13,262=0,140 \times 1+0,198 \times 2$}

Keterangan:

a. Konstanta sebesar 13,262 menyatakan bahwa jika variabel independen (Disiplin kerja dan Pemberian Insentif) dianggap konstan, maka kinerja karyawan adalah sebesar 13,262.

1. Koefisien regresi variabel disiplin kerja mempengaruhi kinerja karyawan sebesar 0,140 atau berpengaruh secara positif yang artinya jika variabel disiplin kerja meningkat, maka berpengaruh terhadap kinerja karyawan dan akan meningkat sebesar 0,140.

2. Koefisien regresi variabel pemberian insentif mempengaruhi kinerja karyawan sebesar 0,198 atau berpengaruh secara positif yang artinya jika variabel pemberian insentif meningkat, maka berpengaruh terhadap kinerja karyawan dan akan meningkat sebesar 0,198.

\subsection{Hasil Uji Koefisien Korelasi}

Tabel 4.9Uji Koefisien Korelasi (R )

Model Summary

\begin{tabular}{|c|c|c|c|c|}
\hline Model & $\mathrm{R}$ & R Square & Adjusted R Square & $\begin{array}{c}\text { Std. Error of the } \\
\text { Estimate }\end{array}$ \\
\hline
\end{tabular}




\begin{tabular}{|l|r|r|r|r|}
\hline 1 & $.336^{\mathrm{a}}$ & .113 & .080 & 1.682 \\
\hline
\end{tabular}

a. Predictors: (Constant), total_x2, total_x1

b. Dependent Variable: total_y

Sumber data diolah dengan SPSS V.23

Berdasarkan tabel 4.9, diperoleh hasil koefisien korelasi $(\mathrm{R})=0,336$ atau 33,6\%. Dari hasil perhitungan tersebut menunjukan bahwa tingkat keeratan variabel X ke Variabel Y lemah (tidak kuat).

\subsection{Hasil Uji Koefisien Determinasi $\left(R^{2}\right)$}

Tabel 4.10 Koefisien Determinasi $\left(\mathrm{R}^{2}\right)$

\begin{tabular}{|l|r|r|r|r|}
\hline \multicolumn{1}{|c|}{ Model Summary $^{\mathbf{b}}$} & \multicolumn{2}{c|}{$\begin{array}{c}\text { Std. Error of the } \\
\text { Estimate }\end{array}$} \\
\hline Model & $\mathrm{R}$ & \multicolumn{1}{c|}{ R Square } & Adjusted R Square & 1.682 \\
\hline
\end{tabular}

a. Predictors: (Constant), total_x2, total_x1

b. Dependent Variable: total_y

Sumber data diolah dengan SPSS V.23

Berdasarkan tabel 4.10 menunjukan bahwa nilai $\mathrm{R}^{2}$ sebesar 0,113 atau $11,3 \%$ menunjukan bahwa variabel kinerja karyawan yang dapat dijelaskan oleh Disiplin Kerja dan Pemberian insentif adalah $11,3 \%$, sedangkan sisanya 0,887 atau $88,7 \%$ dijelaskan oleh faktor-faktor lain yang tidak disertakan dalam penelitian ini.

a) $R=$ Hubungan antara variabel $X_{1}$ dan $X_{2}$ dan terhadap $Y$

sebesar 33,6\%

b) $\mathrm{R}^{2}=$ Keeratan antara variabel $\mathrm{X}$ dan $\mathrm{Y}$ sebesar $11,3 \%$.

\subsection{Diskusi}

1. Pengaruh Disiplin Kerja terhadap Kinerja Karyawan PT. Putra Karisma Palembang

Pengaruh disiplin kerja terhadap kinerja karyawan PT. Putra Karisma Palembang menunjukan hasil tidak ada pengaruh yang signifikan secara parsial antara disiplin kerja terhadap kinerja karyawan PT. Putra Karisma Palembang, hal ini dibuktikan oleh hasil perhitungan t hitung variabel disiplin kerja $\left(\mathrm{X}_{1}\right)$ sebesar 1,753<t tabel 2,005 dengan nilai signifikansi 0,085 yang artinya hipotesis ditolak, Disiplin kerja dalam penelitian ini terbukti secara parsial memberikan kontribusi yang tidak signifikan dalam mempengaruhi kinerja karyawan pada PT. Putra 
Karisma Palembang, dalam hal ini semua faktor Disiplin Kerja yang meliputi Mematuhi semua aturan perusahaan, datang dan pulang tepat waktu, tanggung jawab dalam pekerjaan, menggunakan atribut dan seragam yang sesuai dengan peraturan serta absensi yang baik belum tentu dapat meningkatkan kinerja karyawan, hal ini menunjukan bahwa seberapa tinggi kedisiplinan seorang karyawan tidak mempengaruhi kinerja nya, penjelasan diatas bertentangan dengan pendapat Suprapto yang menjelaskan bahwa dalam pengukuran kinerja, karyawan sangat dituntun untuk dapat menjalankan pekerjaan dengan disiplin kerja yang tinggi untuk dapat melakukan pekerjaan sesuai dengan peraturan-peraturan yang berlaku pada suatu instansi atau perusahaan. Sesuai dengan penelitian terdahulu yang dilakukan oleh Satedjo (2017), Pengaruh Kompensasi dan Disiplin Kerja Terhadap Kinerja Karyawan PT. Modern Widya Technical Cabang Jayapura hasil penelitian menyatakan bahwa Disiplin Kerja tidak berpengaruh signifikan terhadap kinerja karyawat PT. Modern Widya Technical Cabang Jayapura, Disiplin kerja memiliki 9 dimensi yang diuji. Artinya bahwa disiplin kerja dalam hal ini berbicara mengenai jam kerja karyawan, dimana masih ada karyawan yang dating dan pulang tidak sesuai jam kerja perusahaan, namun permalsahan tersebut ternyata tidak mempengaruhi kinerja karyawan, hal ini berati karyawan masih bisa mempertahankan kinerjanya meskipun mereka dating terlambat dan pulang lebih cepat.

\section{Pengaruh Pemberian Insentif Terhadap Kinerja Karyaan PT. Putra Karisma Palembang}

Pemberian insentif terhadap kinerja karyawan PT. Putra Karisma menunjukkan hasil tidak ada pengaruh yang signifikan secara parsial antara pemberian insentif terhadap kinerja karyawan PT. Putra Karisma Palembang, hal ini dibuktikan dari hasil perhitungan t hitung variabel pemberian insentif (X2) sebesar 1,944 < t tabel 2,005 dengan nilai signifikansi 0,057 yang artinya hipotesis ditolak, adanya insentif yang diberikan pemimpin perusahaan belum tentu dapat meningkatkan kinerja seorang karyawan, dengan adanya insentif karyawan akan terus mencoba untuk lebih baik lagi dalam bekerja, hal ini menandakan bahwa karyawan PT. Putra Karisma hanya sedikit menggunakan insentif sebagai alat ukur kinerja mereka, pemberian insentif adalah salah satu hal pokok yang harus diperhatikan oleh perusahaan karena semangat tidaknya karyawan bisa juga disebabkan oleh besar memadai atau tidaknya insentif, hasil penelitian ini tidak sejalan dengan penelitian terdahulu yang dilakukan oleh Dori Mittra Candana (2018), Pengaruh Disiplin kerja, Lingkungan Kerja dan Insentif Terhadap Kinerja Karyawan PT. Incasi Raya Muaro Sakai Kecamatan Pancung Soal Kabupaten Pesisir Selatan yang hasil penelitiannya menyatakan bahwa terdapat pengaruh yang signifikan antara pemberian insentif terhadap kinerja karyawan, hubungan ini dimaknai jika semakin tinggi tingkat insentif yang diberikan organisasi kepada karyawan dalam mendukung pelaksanaan pekerjaanya, maka hal ini akan berdampak semakin tinggi kinerja yang akan dihasilkan oleh karyawn tersebut.

3. Pengaruh Disiplin Kerja dan Pemberian Insentif terhadap Kinerja Karyawan PT. Putra Karisma Palembang

Disiplin Kerja dan Pemberian Insentif terhadap kinerja karyawan di peroleh hasil uji F dengan nilai $\mathrm{F}$ hitung 3,434 > f tabel 3,16, taraf signifikansi lebih kecil dari $0,05(0,039<0,05)$. Hal ini menujukkan variabel disiplin kerja dan pemberian insentif secara silmultan berepengaruh positif dan signifikan terhadap kinerja karyawan PT. Putra Karisma Palembang yang artinya hipotesis diterima, Hal ini sejalan dengan pendapat yang dikemukakan oleh Hasibuan (2013:34) bahwa secara garis besar faktor yang mempengaruhi kinerja adalah faktor internal dan eksternal. Faktor internal merupakan faktor yang berasal dari dalam diri karyawan, yaitu intelektualitas, 
disiplin kerja, pengalaman kerja dan latar belakang pendidikan. Sedangkan faktor eskternal adalah faktor pendukung dari luar karyawan yaitu gaya kepemimpinan, pengembangan karir, lingkungan kerja, pelatihan, kompensasi, insentif, dan system manajemen didalam perusahaan, didalam penelitian ini disiplin kerja dan pemberian insentif dipilih sebagai variabel bebas yang mempengaruhi kinerja karyawan karena kesesuain permasalahan dengan objek yang diteliti agarnya perusahaan memperhatikan disiplin kerja dan pemberian insentif terhadap karyawan karena kedua hal tersebut apabila diterapkan dengan baik secara bersama-sama maka akan memberikan dampak positif yang akan berpengaruh terhadap kinerja karyawan. Penelitian ini sejalan dengan penelitian terdahulu yang dilakukan oleh Handoko dan Waluyo (2017) hasil uji secara simutan menyatakan adanya pengaruh signifikan antara variabel disiplin kerja dan pemberian insentif terhadap kinerja karyawan, artinya semakin tinggi frekuensi disiplin kerja dan semakin tinggi pemberian insentif didalam sebuah perusahaan akan berdampak semakin tinggi kinerja karyawan.

\section{Kesimpulan}

1. Dari hasil penelitian diperoleh $\mathrm{t}$ hitung variabel disiplin kerja $\left(\mathrm{X}_{1}\right)$ sebesar $1,753<\mathrm{t}$ tabel 2,005 dengan nilai signifikansi 0,085. Hal ini menujukkan variabel disiplin kerja secara parsial tidak berpengaruh signifikan terhadap kinerja karyawan PT. Putra Karisma Palembang, penelitian ini sejalan dengan penelitian yang dilakukan oleh (Satedjo, 2017) yang berjudul Pengaruh Kompnsasi dan Disiplin Kerja Terhadap Kinerja Karyawan PT. Modern Widya Tehnical Cabang Jayapura yang menyatakan bahwa disiplin kerja tidak berpengaruh signifikan terhadap kinerja karyawan.

2. Dari hasil penelitian diperoleh $t$ hitung variabel pemberian insentif $\left(\mathrm{X}_{2}\right)$ sebesar $1,944<\mathrm{t}$ tabel 2,005 dengan nilai signifikansi $0,057 \mathrm{Hal}$ ini menujukkan variabel pemberian insentif secara parsial tidak berpengaruh signifikan terhadap kinerja karyawan PT. Putra Karisma Palembang, penelitian ini sejalan dengan penelitian yang dilakukan oleh (Wardhana 2015) yang berjudul Pengaruh Motivasi, insentif dan pengembangan karis terhadap kinerja karyawan PT. Telkomsel Grapari Pemuda Surabaya yang menyatakan bahwa pemberian insentif tidak berpengaruh signifikan terhadap kinerja karyawan.

3. Dari hasil penelitian yang di lakukan secara simultan terhadap variabel disiplin kerja dan pemberian insentif di peroleh hasil uji $\mathrm{F}$ dengan nilai $\mathrm{F}$ hitung 3,434 $>\mathrm{f}$ tabel 3,16, taraf signifikansi lebih kecil dari $0,05(0,039<0,05)$. Hal ini menujukkan variabel disiplin kerja dan pemberian insentif secara silmultan berepengaruh signifikan terhadap kinerja karyawan PT. Putra Karisma Palembang.

\section{Referensi}

A. A. Anwar Prabu Mangkunegara, (2016). Manajemen Sumber Daya Manusia Perusahaan. Bandung : PT. Remaja Rosda karya kedua belas.

Anggrainy, I, F., Darsono, N., \& Putra, T.R.I (2017) Pengaruh fasilitas kerja, disiplin kerja dan kompensasi terhadap motivasi kerja implikasinya pada prestasi kerja pegawai negeri sipil badan kepegawaian pendidikan dan pelatihan Provinsi Aceh Jurnal Magister Manajemen, I(1), $1-10$.

Ayu, D. K.,\& Sinaulan, J. H. (2018). Pengaruh Insentif dan Disiplin Kerja terhadap Kinerja Karyawan pada PT. Bintang Satoe Doea Jurnal Ekonomi, 20(3), 373-383.

Baharuddin, A., Alhabsyi, T., \& Utami, H. N. (2013) PENGARUH PELATIHAN 
KOMPENSASI DAN DISIPLIN KERJA TERHADAP PRESTASI KERJA KARYAWAN (Studi Pada Kantor PT. PLN (Pesrsero) Area Pelayanan dan Jaringan Malang). Jurnal Profit, 6(2), 56-68.

Candana, D.M. (2018) Pengaruh Disiplin Kerja, Lingkungan Kerja dan Insentif terhadap Kinerja Karyawan PT. Incasi Raya Muaro Sakai Kecamatan Pancung Soal Kabupaten Pesisir Selatan. Jurnal EKOBISTEK, 7(1),1-8.

Dohaney, J., de Roiste, M., Salmon, R.A., \& Sutherland, K. (2020). Benefits, barriers, and incentives for improved resilience to disruption in university teaching. International Journal of International Journal of Disaster Risk Reduction, 50. https://doi.org/10.1016/j.ijdrr.2020.101691

Eliyana th, A., Ma'arif, S., \& Muzakki. (2019). Job statisfaction and organizational commitment effect in e transformational leadership towards employee performance. European Research on Management and Business Economic. 25(3),144-150. https://doi.org/10.1016/j.iedeen.2019.05.001.

F., Hubeis, A. V., \& Affandi, M.J. (2017). The influence of incentive towards their Motivation and Discipline (A Case Study at Rectorate of Andalas University, West Sumatera, Indonesia). Journal of Education and E-Learning Research, 4(4), 122-128. https://doi.org/10.20448/journal.509.2017.44.122.128.

Ghozali, Imam. (2011) “Aplikasi Analisis Multivariate Dengan Program SPSS”. Semarang: Badan Penerbit Universitas Diponegoro.

Haines et al, 2019, Journal of Chemical Information and Modeling, 53(9), 1689-1699.

Handoko, T., \& Waluyo, H. (2017). Pengaruh Disiplin Kerja dan Pemberian Insentif terhadap Kinerja Karyawan PT. Nusantara Card Semesta ( Studi kasus karyawan divisi sales dan marketing Jakarta). Jurnal Ilmu Administrasi Bisnis SI Undip, 6(3), 87-10

Hartatik, Puji Indah (2014) Buku Praktis Mengembangkan Sumber Daya Manusia, Yogyakarta: Suka Buku.

Hasyim, M.A.N., Maje, G. I. L., Alimah, V. \& Priyadi, S. A. P. (2020). Pengaruh Motivasi dan Disiplin Kerja terhadap kinerja karyawan PT. Kahatex Jesya (Jurnal Ekonomi \& Ekonomi Syariah), 3(2), 58-69. https://doi.org/10.36778/jesya.v3i2.161

Humaira, R. (2019) Pengaruh Upah, Insentif, Jaminan Sosial dan Tunjangan Kesejahteraan terhadap Produktivitas Pegawai Pada Dinas Sosial Provinsi Aceh, (Doctoral dissertation)

Ida Aryati, Y. Y. I (2017) Pengaruh Insentif, Disiplin Kerja, dan komunikasi terhadap kinerja karyawan bagian sewing PT. Pelita Tomangmas Karanganyar, Jurnal Akuntansi dan Pajak, 18(01), 145-157. https://doi.org/10.29040/jap. v18i01.92.

Ismail, F.F., \& Sudarmadi, D. (2019). Pengaruh Sistem Informasi Akuntansi dan Pengendalian Internal Terhadap Kinerja Karyawan PT. Beton Elemen Persada. Jurnal Akuntansi, Audit dan Sistem Informasi Akuntansi, 3(1), 1-13.

Juliani, T., \& Windu, F.S. (2017). Analysis of Incentive, Work Discipline, and Education Levels That Influence Employee Performance. Jurnal Aplikasi Manajemen,15(2),355361.https://doi.org/10.21776/ub.jam.2017.015.02.20.

Karmadita, I., \& Subudi,M.(2014).Pengaruh Kompetensi Dan Kecerdasan Emosional 
Terhadap Kinerja Karyawan Si Doi Hotel Dan Restaurant Legian. E-Jurnal Manajemen Universitas Udayana,3(4), 255097.

Kastalani, M., \& Kerja. P. (2015). Pengaruh Insentif Terhadap Prestasi Kerja Di Badan Penanggulangan Bencana Daerah Kota Samarinda.E-Journal Pemerintahan Integratif, $3(2), 351-364$.

Kusuma, Y. W. (2016). Pengaruh Motivasi Kerja Dan Insentif Terhadap Semangat Kerja Karyawan .Jurnal Ilmu Dan Riset Manajemen, 5(2).

Kurniasari, N. (2014). Hubungan Disiplin Keja,Lingkungan Kerja Dan Kompensasi Terhadap Kepuasan Kerja Dan Kinerja Pada Pegawai Politeknik Kesehatan. Jurnal Eonomi Manajemen Sumber Daya, 15(2), 21-31. 